\title{
Electrical Resistivity and Moisture Content Measurements for Some Concrete Samples ${ }^{\dagger}$
}

\author{
Mihaela Luminiţa Udrea 1, Vanessa Trăistaru 1, Ana-Alexandra Sorescu 1,2,*, \\ Mădălina Elena David 1, Elena Ramona Andrei ${ }^{1}$ and Rodica Mariana Ion ${ }^{1,2}$ \\ 1 National Institute for Research \& Development in Chemistry and Petrochemistry - ICECHIM Bucharest, \\ 202 Spl. Independentei, 060021 Bucharest, Romania; udreamihaela1996@gmail.com (M.L.U.); \\ vanessa.traistaru@gmail.com (V.T.); madalina.e.david@gmail.com (M.E.D.); \\ andreiramona@hotmail.com (E.R.A.); rodica_ion2000@yahoo.co.uk (R.M.I.) \\ 2 Valahia University, Materials Engineering Department, 130004 Târgoviște, Romania \\ * Correspondence: ana-alexandra.sorescu@icechim.ro \\ + Presented at the 15th International Symposium "Priorities of Chemistry for a Sustainable Development" \\ PRIOCHEM, Bucharest, Romania, 30th October-1st November 2019.
}

Published: 15 October 2019

Keywords: electrical resistivity measurements; concrete moisture content; concrete permeability

The aim of this study was to assess the properties of some concrete samples according to their moisture content and, thus, permeability. There are different causes of deterioration of reinforced concrete structures, such as corrosion of reinforcement bars due to carbonation or chloride ingress, freezing and thawing action, sulfate attack, alkali aggregate reaction, and so forth [1].

Studies have shown that resistivity can be directly correlated with chloride diffusion rate. Onsite mapping of the resistivity of a concrete structure will identify the most permeable areas. These areas are more likely to be susceptible to chloride penetration [2].

Resistivity measurements may be used on site to determine premature drying of concrete. This application is particularly important, as premature drying can lead to structural weakening [3].

Here, the electrical resistivity of concrete samples was measured using a Resipod Proceq with a $50 \mathrm{~mm}$ probe spacing model at room temperature in an indoor climate. Four types of samples were used for measurement: a simple concrete one, concrete with nails, concrete with thick wire (steel), and concrete with thin wire.

Empirical studies have shown that resistivity is directly linked to the likelihood of corrosion. When the electrical resistivity of concrete is low, the likelihood of corrosion increases. When the electrical resistivity is high, the likelihood of corrosion decreases. Figure 1 shows that electrical resistivity values were between 4 and $50 \mathrm{k} \Omega \mathrm{cm}$, corresponding to a moderate risk of corrosion for most measurements and a high risk of corrosion for six of the measurements. Figure 2 shows the capillarity measurements for the same samples, which provide a better understanding of the water penetration phenomenon occurring inside the concrete.

The obtained results can be used for mapping out areas of various wetness and dryness degrees and assessing which areas of the concrete samples are more likely to be permeable. Identifying these particular areas is necessary because they are more likely to be susceptible to chloride penetration, leading to a more pronounced structural degradation of the concrete. 


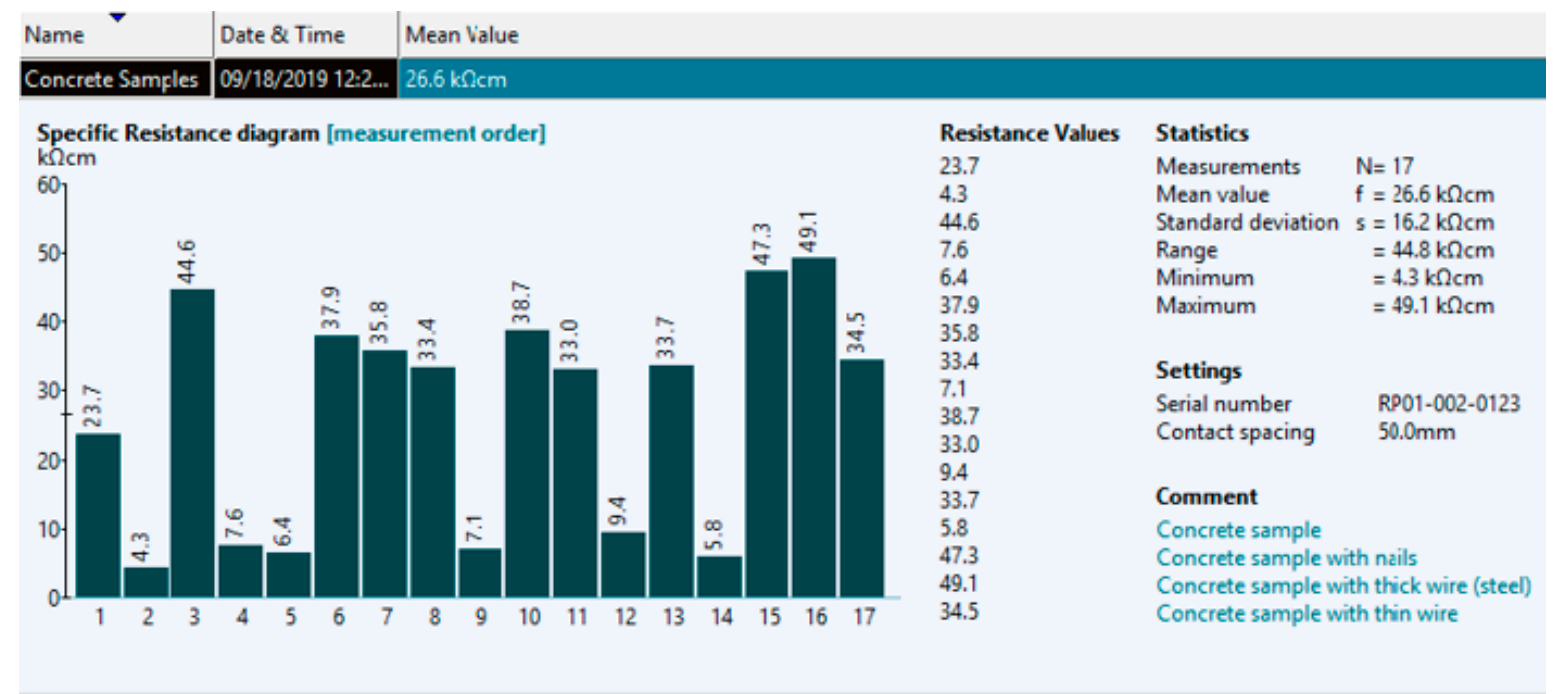

Figure 1. Electrical resistivity measurements of concrete samples.

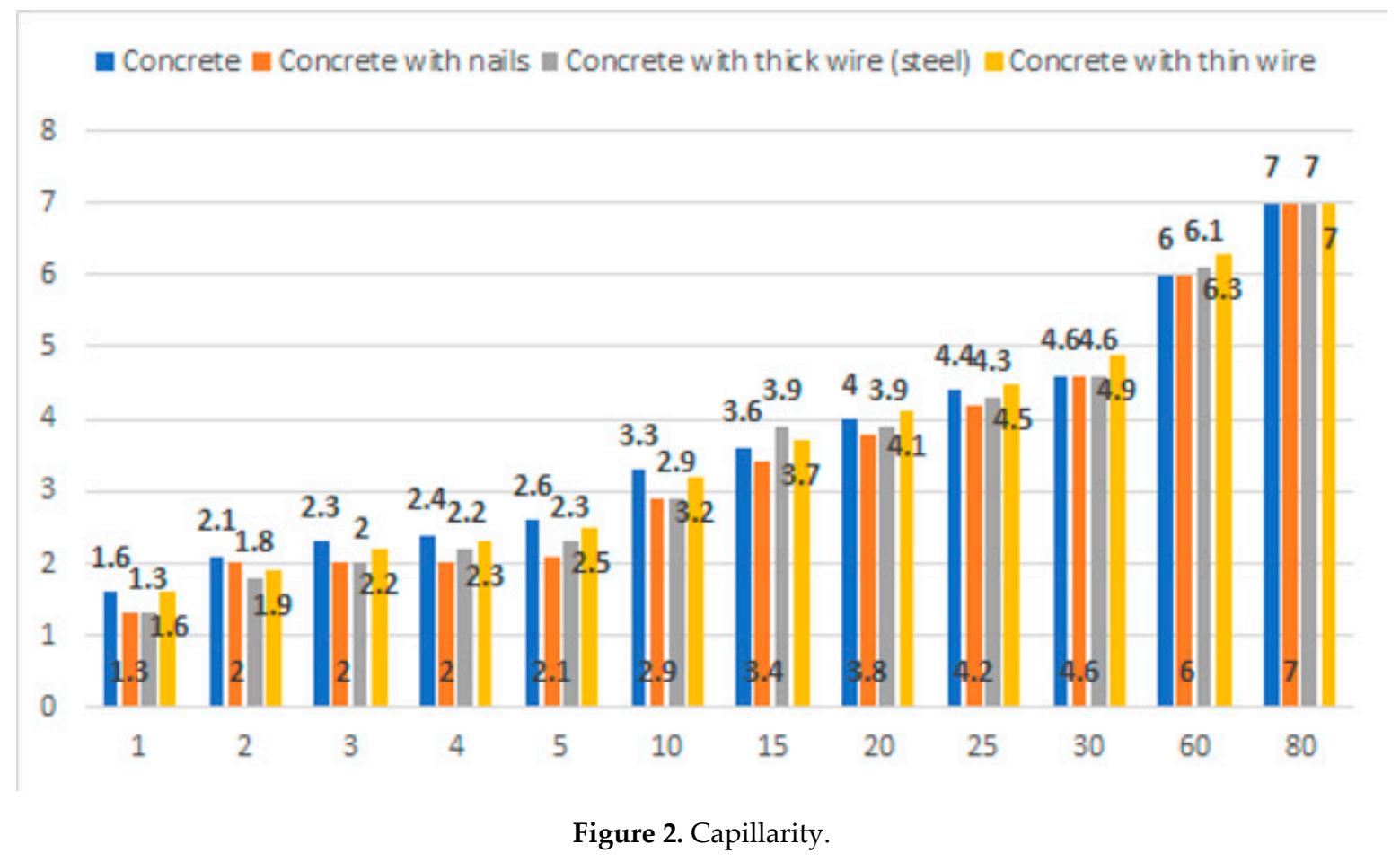

Acknowledgments: The work on this paper was supported by the Government of Romania, Ministry of Research and Innovation, Project PN19.23.03.01.04, 51PCCDI/2018, and 5PS/2019.

\section{References}

1. Basheer, L.; Kropp, J.; Cleland, D.J. Assessment of the durability of concrete from its permeation properties: A review. Constr. Build. Mater. 2001, 93, 103-115.

2. Layssi, H.; Alizadeh, A.R.; Ghods, P.; Salehi, M. Electrical Resistivity of Concrete. Concr. Int. 2015, 37, 41-46.

3. Su, J.K.; Yang, C.C.; Wu, W.B.; Huang, R. Effect of moisture content on concrete resistivity measurement. J. Chin. Inst. Chem. Eng. 2011, 25, 117-122.

(C) 2019 by the authors. Licensee MDPI, Basel, Switzerland. This article is an open access article distributed under the terms and conditions of the Creative Commons Attribution (CC BY) license (http://creativecommons.org/licenses/by/4.0/). 